\title{
QTe prolongation in patients with hearing loss: Electrocardiographic and genetic study
}

\author{
Agnieszka Sanecka ${ }^{1}$, Elżbieta Katarzyna Biernacka², Małgorzata Szperl ${ }^{3}$, \\ Magdalena Sosna ${ }^{4}$, Małgorzata Mueller-Malesińska ${ }^{4}$, Urszula Kozicka², \\ Rafał Baranowski ${ }^{5}$, Agnieszka Kosiec ${ }^{3}$, Hubert Łazarczyk ${ }^{6}$, Henryk Skarżyński ${ }^{4}$, \\ Piotr Hoffman ${ }^{2}$, Katarzyna Bieganowska ${ }^{7}$, Ryszard Piotrowicz ${ }^{1}$ \\ ${ }^{1}$ Department and Clinic of Cardiac Rehabilitation and Noninvasive Electrocardiology, \\ Institute of Cardiology, Warsaw, Poland \\ ${ }^{2}$ Department of Congenital Cardiac Defects, Institute of Cardiology, Warsaw, Poland \\ ${ }^{3}$ Molecular Biology Laboratory, Institute of Cardiology, Warsaw, Poland \\ ${ }^{4}$ Institute of Physiology and Pathology of Hearing, World Hearing Center, Nadarzyn, Poland \\ ${ }^{5}$ Department of Arrhythmia, Institute of Cardiology, Warsaw, Poland \\ ${ }^{6}$ Institute of Cardiology, Warsaw, Poland \\ ${ }^{7}$ Department of Cardiology, Children's Memorial Health Institute, Warsaw, Poland
}

\begin{abstract}
Background: The aim of the study was to determine, whether electrocardiogram (ECG) screening could reduce the risk of sudden cardiac death in patients with hearing loss through the early diagnosis of Jervell and Lange-Nielsen syndrome and the introduction of the therapy. Methods: One thousand and eighty patients with hearing loss (aged $21.8 \pm 19.9$ years) underwent ECG. Additionally, all subjects were asked to complete a 3-question survey. Those who met, at least, one of the high-risk criteria underwent further cardiac assessment and genetic testing.
\end{abstract}

Results: QTc assessment was possible in 1,027 patients. Mean QTc measured $422.8 \pm 23.7 \mathrm{~ms}$ in 313 women, $414.9 \pm 27.7 \mathrm{~ms}$ in 273 men and $421.1 \pm 21.5 \mathrm{~ms}$ in 441 children (individuals younger than 14 years). Abnormal QTc was found in 13 (4.1\%) women, 20 (7.3\%) men, and $72(16.3 \%)$ children. In the studied group, no recessive mutation of KNCQ1 or KCNE1 was found. In 6 patients, other mutations were found: in $\mathrm{KCNQ} 1(n=1)$, in $\mathrm{KCNH} 2$ $(n=3)$ and in SCN5A $(n=1)$, which were pathogenic for long-QT-syndromes (LQTS), and 2 mutations of unknown clinical significance in SCN5A. Overall, out of these 6 patients LQTS was diagnosed in 3 asymptomatic patients, but with abnormal QTc and in 2 patients with normal QTc, but who were previously treated for epilepsy.

Conclusions: Jervell and Lange-Nielsen syndrome is a very rare condition even in a population with hearing loss. In this population, the prevalence of prolonged QT interval is increased over the general population. Further investigations are necessary. (Cardiol J 2016; 23, 1: 34-41)

Key words: long-QT syndrome, hearing loss, Jervell and Lange-Nielsen syndrome, electrocardiogram

Address for correspondence: Agnieszka Sanecka, MD, Department and Clinic of Cardiac Rehabilitation and Noninvasive Electrocardiology, Institute of Cardiology, ul. Alpejska 42, 04-628 Warszawa, Poland, e-mail: agasa@mp.pl

Received: 14.06.2015 Accepted: 01.09.2015 


\section{Introduction}

The Jervell Lange-Nielsen syndrome (JL-N) (a long-QT-syndrome variant associated with the deafness) is a rare and severe type of long-QT-syndrome (LQTS). It is an inherited autosomal recessive disorder. The disease is caused by the mutations in at least one of the two genes: KCNQ1 or KCNE1. These genes encode alpha and beta subunits of the potassium channel which mediates $\mathrm{I}_{\mathrm{Ks}}$ current [1] and their mutations result in an abnormal function of the potassium channel and subsequent prolongation of the ventricular repolarization phase. The latter predisposes to ventricular tachyarrhythmias such as 'torsade de pointes' or ventricular fibrillation and can lead to fainting, syncope or sudden cardiac death. The JL-N syndrome is characterized by high mortality in young age (27\% of sudden deaths occur by the age of 8.5 years). Sudden cardiac death is often the first manifestation of the heart being involved in the disease process [1]. Electrocardiography (ECG) changes, like an extremely abnormal repolarization pattern and a very long QTc interval $(557 \pm 65 \mathrm{~ms})$, typically occur very early in life [1]. The presence of such changes in a person with the hearing loss immediately raises a suspicion of a JL-N syndrome and allows implementation of prophylactic lifesaving treatment. Besides the British Association of Paediatricians in Audiology (BAPA) and British Association of Audiological Physicians (BAAP) to screen every patient with congenital hearing loss with ECG, other organizations do not recommend routine ECG in this group of patients [2]. However, guidelines clearly do emphasize ECG utility in patients with a history of loss of consciousness, arrhythmia or family history of sudden death [3].

The aim of this study was to determine whether ECG screening could reduce the risk of sudden cardiac death in patients with hearing loss through an early diagnosis of JL-N syndrome and introduction of the therapy. ECG studies were performed in patients with hearing loss to identify subjects with long QTc interval (LQT). Subsequently, LQT (including JL-N) syndromes were confirmed by cardiac and genetic testing. Theoretically, an early identification of JL-N syndrome would allow an introduction of appropriate treatment and prevention of serious arrhythmias or sudden cardiac death.

\section{Methods}

\section{Studied population}

In the prospective manner, 1,080 patients were enrolled from two outpatient audiology clinics and three schools for children with hearing loss. Studied population consisted of 562 (52\%) females and 518 (48\%) males with confirmed hearing loss, aged $21.8 \pm 19.9$ years $(0.16-84$ years $)$. It also included $454(42 \%)$ children aged less than 14 years. All underwent a 12-lead ECG.

For the purpose of the study, we used the following criteria for hearing loss: sensorineural hearing loss of $30 \mathrm{~dB}$ HL or more (calculated as average hearing thresholds for frequencies relevant to speech understanding $500 \mathrm{~Hz}, 1000 \mathrm{~Hz}$, $2000 \mathrm{~Hz}$ and $4000 \mathrm{~Hz}$ ). Of all studied, 301 patients had cochlear implants. 707 patients were divided into six groups according to the type and the degree of hearing loss per audiological data. These were only available in patients from outpatient clinics we had no access to the precise audiological data of children examined at schools. The majority of patients $(n=525)$ had congenital sensorineural bilateral hearing loss and were divided into four groups: 1) patients with bilateral significant or profound sensorineural hearing loss (defined as the average hearing threshold of $70 \mathrm{~dB}$ HL or more at frequencies: $500 \mathrm{~Hz}, 1000 \mathrm{~Hz}, 2000 \mathrm{~Hz}$, and $4000 \mathrm{~Hz}$, and not meeting criteria for the forth group) $(\mathrm{n}=426), 2)$ medium-grade sensorineural hearing loss (defined as the average hearing threshold between $69 \mathrm{~dB} \mathrm{HL}$ and $50 \mathrm{~dB} \mathrm{HL}$ at frequencies: $500 \mathrm{~Hz}, 1000 \mathrm{~Hz}, 2000 \mathrm{~Hz}$, and $4000 \mathrm{~Hz}$, and not meeting criteria for the fourth group) $(\mathrm{n}=55)$, 3) low-grade sensorineural hearing loss (defined as the average hearing threshold between $49 \mathrm{~dB} \mathrm{HL}$ and $30 \mathrm{~dB}$ at frequencies: $500 \mathrm{~Hz}, 1000 \mathrm{~Hz}, 2000 \mathrm{~Hz}$, and $4000 \mathrm{~Hz}$, and not meeting criteria for the fourth group) $(\mathrm{n}=17)$, 4) bilateral partial deafness (patients with low-frequency residual hearing, defined as the average hearing threshold of $60 \mathrm{~dB}$ $\mathrm{HL}$ at frequencies: $125 \mathrm{~Hz}, 250 \mathrm{~Hz}$, and $500 \mathrm{~Hz}$ ) $(\mathrm{n}=27)$. Additionally, there were 182 patients with hearing loss of unknown cause: group 5) patients with a history of an episode of idiopathic sudden deafness $(\mathrm{n}=19), 6)$ with acquired varying degrees of bilateral sensorineural hearing loss of unknown etiology $(\mathrm{n}=163)$.

\section{Electrocardiographic testing}

All 1,080 patients underwent a 12-lead ECG. ECG recordings (recorded with a sampling frequency of $1000 \mathrm{~Hz}$ ) were performed in the outpatient Audiology Departments and schools and sent for the evaluation to the cardiology center using the Cardiology Information Management System Sentinel Reynolds Medical. ECG evaluation was done by a single observer (cardiologist). QT interval 
measurements were performed electronically on the $5 \times$ enlarged views of evolutions with an accuracy of $1 \mathrm{~ms}$. The QT interval was measured in the same cardiac cycle in at least three leads (usually in leads: II, V2, and V5). To correct the QT interval for heart rates between 50 and 120 bpm Bazett's formula was used. For faster and slower heart rates Hodges formula was used. Heart rate was calculated based on the RR interval measurement. We selected the RR interval preceding the QRS complex - the one for which QT interval was being measured. Patients with QRS complexes of $120 \mathrm{~ms}$ or more were excluded from the average QTc calculation. Fifty-three recordings were excluded from the calculation of the mean QTc due to the presence of any of the following: pre-excitation pattern, intraventricular conduction block, QRS complexes measuring $120 \mathrm{~ms}$ or more, ventricular pacing or artifacts, as all these could prevent reliable QTc determination. Based on differences in physiology of cardiac conduction and inherent varying reference values for QTc between children and adults, males and females, study population was divided into 3 categories: 1) 454 (42\%) children younger than 14 years (232 were girls), 2) $330(30.5 \%)$ females 14 or more years old and 3) $296(27.5 \%)$ males 14 or more years old [4]. All subjects were asked to complete a 3-question survey on the presence of 1 ) personal history of loss of consciousness or fainting associated with palpitations, 2) personal history of epilepsy, 3) family history of the sudden death or loss of consciousness. Based on the number of positive answers, and calculated QTc length some subjects were rated as "high-risk". Specific criteria for such rating were: 1) positive response to all 3 questions in the survey, 2) any 2 positive responses and QTc longer than $440 \mathrm{~ms}, 3$ ) QTc longer than $455 \mathrm{~ms}$. Patients rated as "high-risk" attended further cardiac evaluation including ECG exercise testing, 24-h Holter-ECG, and genetic testing. During exercise testing the occurrence of ventricular arrhythmias and QTc length (before exercise, at peak exercise and after exercise test) were evaluated. Holter results were assessed for the presence of ventricular arrhythmias. Automatic measurement and calculation of the QT and QTc intervals was performed wherever possible.

\section{Genotyping}

DNA was isolated from peripheral blood leukocytes using the phenol method. Four genes were sequenced: $K C N Q 1, K C N H 2, S C N 5 A$, and $K C N E 1$. We used the Next-Generation Sequencing and traditional Sanger method. Analysis was per- formed on the Amplicon Variant Analysis software. Primers used in genotyping were designed in the Laboratory of Molecular Biology of the Institute of Cardiology and they are available upon request. The presence of the pathogenic mutations was confirmed with Sanger method.

\section{Consenting and approval}

The Bioethics Committee of the Institute of Cardiology approved the project. All enrolled patients (or when applicable their legal guardians) have given their written informed consent to participate. Written informed consent has been additionally received from patients rated as highrisk who agreed to participate in further steps of the study.

\section{Results}

\section{Characteristics of the study population}

Electrocardiogram was analyzed in 1,080 patients (53 recordings were excluded from the calculation of the mean QTc due to the presence of any of the following: pre-excitation pattern, intraventricular conduction block, QRS complexes measuring $120 \mathrm{~ms}$ or more, ventricular pacing or artifacts). The survey was completed by 887 (82\%) patients; 107 out of 887 subjects reported a loss of consciousness or palpitations associated with fainting, 40 subjects were diagnosed with epilepsy and 46 people had a family history of sudden death or loss of consciousness. Altogether 96 (8.9\%) patients met criteria for the high risk: 6 patients met the $1^{\text {st }}$ criterion, 3 patients met the $2^{\text {nd }}$ criterion, and 88 patients met the $3^{\text {rd }}$ criterion.

\section{Electrocardiogram}

The results of the QTc calculations, with an accuracy of $1 \mathrm{~ms}$, are demonstrated in Table 1 .

In females 14 years old and older mean QTc was $422.8 \pm 23.7 \mathrm{~ms}$, ranging from $352 \mathrm{~ms}$ to $495 \mathrm{~ms}$. Out of these females, $13(4.1 \%)$ had QTc exceeding the reference value. Their mean QTc was $472.2 \pm$ $\pm 10.1 \mathrm{~ms}$. In males 14 years old and older, mean QTc was $414.9 \pm 27.7 \mathrm{~ms}$, ranging from $343 \mathrm{~ms}$ to $517 \mathrm{~ms}$. Out of these males, $20(7.3 \%)$ had prolonged QTc with a mean value of $467.8 \pm 16.4 \mathrm{~ms}$ and 1 male had QTc longer than 500 ms. Mean QTc interval in children (individuals younger than 14 years old) was $421.1 \pm 21.5 \mathrm{~ms}$, ranging from $366 \mathrm{~ms}$ to $483 \mathrm{~ms}$. QTc exceeding $440 \mathrm{~ms}$ was observed in $72(16.3 \%)$ children. However, the QTc prolongation did not exceed $500 \mathrm{~ms}$. Therefore, nobody was diagnosed with LQTS meeting solely a "QTc 
Table 1. The results of QTc measurements by enlarged evolution method with an accuracy of $1 \mathrm{~ms}$.

\begin{tabular}{|c|c|c|c|c|c|}
\hline & $\begin{array}{l}\text { Minimal } \\
\text { QTc } \\
\text { [ms] }\end{array}$ & $\begin{array}{l}\text { Maximal } \\
\text { QTc } \\
\text { [ms] }\end{array}$ & $\begin{array}{l}\text { Mean } \\
\text { QTc } \pm \text { SD } \\
{[\mathrm{ms}]}\end{array}$ & $\begin{array}{l}\text { Number of } \\
\text { subjects with QTc } \\
\text { above the normal } \\
\text { range (\% of the } \\
\text { group)* }\end{array}$ & $\begin{array}{c}\text { Mean QTc } \pm \text { SD in } \\
\text { subjects with QTc } \\
\text { above the normal } \\
\text { range [ms]* }\end{array}$ \\
\hline Female $\geq 14$ years of age $(n=313)$ & 352 & 495 & $422.8 \pm 23.7$ & $13(4.1 \%)$ & $472.2 \pm 10.1$ \\
\hline Male $\geq 14$ years of age $(n=273)$ & 343 & $517 * *$ & $414.9 \pm 27.7$ & $20(7.3 \%)$ & $467.8 \pm 16.4$ \\
\hline Children $<14$ years of age $(n=441)$ & 366 & 483 & $421.1 \pm 21.5$ & $72(16.3 \%)$ & $454.0 \pm 11.8$ \\
\hline
\end{tabular}

${ }^{*}$ Normal QTc range: $\leq 460 \mathrm{~ms}$ in women, $\leq 450 \mathrm{~ms}$ in men, $\leq 440 \mathrm{~ms}$ in children under 14 years of age; ${ }^{*}$ QTc $>500 \mathrm{~ms}$ was found in one male; SD - standard deviation

Table 2. The results of QTC in other cardiac investigations in high-risk patients that attended their appointment.

\begin{tabular}{lcc}
\hline & QT \pm SD $[\mathrm{ms}]$ & QTc \pm SD $[\mathrm{ms}]$ \\
\hline ECG $(\mathrm{n}=50)$ & $388.76 \pm 31.48$ & $411.86 \pm 24.02$ \\
ECG exercise test $(\mathrm{n}=40):$ & $364 \pm 32.27$ & $412 \pm 31.56$ \\
$\quad$ Rest & $255 \pm 32.52$ & \\
Peak exercise & $346 \pm 34.33$ & $441 \pm 35.05$ \\
$\quad$ Recovery & & \\
Holter ECG $(\mathrm{n}=35):$ & $380.94 \pm 30.7$ & $432.77 \pm 21.35$ \\
$\quad$ Mean & $435.68 \pm 35.49$ & $509.55 \pm 35.47$ \\
$\quad$ Maximal & & \\
Percentage of patients with certain QTc values: & $4.08 \%$ & \\
$>440 \mathrm{~ms}$ & $3.80 \%$ & \\
$>460 \mathrm{~ms}$ & $2.45 \%$ & \\
$>470 \mathrm{~ms}$ & $2.34 \%$ & \\
$>480 \mathrm{~ms}$ & $0.97 \%$ & \\
$>500 \mathrm{~ms}$ & & \\
\hline
\end{tabular}

ECG - electrocardiogram; SD - standard deviation

length" criterion. In the entire study population, no statistically significant correlation between hearing loss pattern and the presence of QTc prolongation was found $(\mathrm{p}=0.0596)$. From the 96 patients who fulfilled the criteria of the high-risk group, 62 attended follow-up appointments. The automatic calculation of the QT and QTc intervals throughout the $24 \mathrm{~h}$ period was performed in 35 subjects with Holter monitoring. In 7 patients, periodic QTc prolongation of up to $643 \mathrm{~ms}$ was found. It was present in less than $1 \%$ of monitoring time. Two other patients had an abnormal QTc response to exercise. However, none of these patients had syncope or arrhythmia. Before genotyping was completed, LQTS diagnosis was made in 3 asymptomatic patients based on the history, another ECG, exercise testing and Holter monitor- ing (HRS/EHRA/APHRS Expert Consensus 2013 criteria were used) (Table 2) [5].

\section{Other ECG abnormalities}

We analyzed the incidence of other ECG abnormalities in the study population. We found atrial rhythm in 15 patients, wandering atrial pacemaker in 2 patients, sinus bradycardia in 125 patients, atrial fibrillation in 3 patients, first-degree atrioventricular block in 19 patients, signs of pre-excitation in 2 patients, right bundle branch block (complete or incomplete) in 39 patients, left anterior fascicular block in 12 patients, complete left bundle branch block in 2 patients, nonspecific intraventricular conduction disturbances in 35 patients, signs of left atrial hypertrophy in 24 patients, signs of myocardial ischemia in 5 patients, and signs of myocardial necrosis in 4 patients. 
Table 3. Mutations found in high-risk patients with hearing loss.

\begin{tabular}{|c|c|c|c|c|}
\hline Gender, age [years] & $\begin{array}{l}\text { High-risk criteria } \\
\text { fulfilled }\end{array}$ & QTc [ms] & Gene, exon & Amino acid changes \\
\hline Female, 15 & Asymptomatic & 480 & KCNQ1 exon 13 & R555H, pathogenic \\
\hline \multirow[t]{3}{*}{ Female, 13} & Syncope & 396 & $K C N H 2$ exon 13 & R1047L, pathogenic \\
\hline & Epilepsy & & & \\
\hline & Family history & & & \\
\hline \multirow[t]{3}{*}{ Male, 19} & Syncope & 352 & KCNH2 exon 13 & R1047L, pathogenic \\
\hline & Epilepsy & & $S C N 5 A$ exon 2 & R53Q, of unknown \\
\hline & Family history & & & $\begin{array}{l}\text { clinical significance, } \\
\text { one previous report }\end{array}$ \\
\hline \multirow[t]{3}{*}{ Female, 21} & Syncope & 435 & SCN5A exon 17 & Q1033R, of unknown \\
\hline & Epilepsy & & & $\begin{array}{l}\text { clınıcal sıgnificance, } \\
\text { not tested previously }\end{array}$ \\
\hline & Family history & & & \\
\hline Female, 39 & Asymptomatic & 467 & $S C N 5 A$ exon 28 & P2005A, pathogenic \\
\hline Male, 62 & Asymptomatic & 481 & KCNH2 exon 13 & R1047L, pathogenic \\
\hline
\end{tabular}

\section{Genotyping}

Sixty blood samples for genetic testing were obtained. We have not found recessive mutations of KNCQ1 or KCNE1 typical for JL-N in any of the studied subjects. However, in 6 (10\% of all genotyped) patients we have found other pathogenic mutations in the KCNQ1 (1), KCNH2 (3), and SCN5A (1) genes and two mutations of unknown clinical significance, both in the SCN5A gene (Table 3). Three of these 6 patients had the R1047L mutation in the $\mathrm{KCNH} 2$ gene, which is associated with the LQTS type 2 (LQT2). One of those 6 patients had coexistent R1047L mutation in the $\mathrm{KCNH} 2$ gene with the R53Q mutation of unknown clinical significance in the SCN5A gene, which had been previously reported only once. Separately, 3 of those 6 patients were earlier diagnosed with epilepsy. Finally, in 2 subjects of those 3 patients we have made the diagnosis of LQT2. These patients had been earlier incorectly diagnosed with epilepsy and were unsuccessfully treated with antiepileptic drugs. Both of these patients fulfilled first highrisk criterion: they both had a history of loss of consciousness, previous diagnosis of epilepsy and a positive family history, and they had no significant QT prolongation: $396 \mathrm{~ms}$ and $352 \mathrm{~ms}$, respectively. In other 3 patients, LQTS type 1, 2 and 3 have been diagnosed, respectively. Out of other 2 of those 6 patients, 1 was found to have aP2005A mutation in the SCN5A gene, and another 1 had a R1047L mutation in the $\mathrm{KCNH} 2$ gene. They did not present any other symptoms of LQTS, despite significant QTc prolongation. In the last one of those 6 patients, who previously had been diagnosed with epilepsy and alpha-mannosidosis and who had QTc of $435 \mathrm{~ms}$, a Q1033R mutation in exon 17 of the SCN5A gene was detected. This mutation has unknown clinical significance. The patient has not been diagnosed with LQTS.

\section{Polymorphisms}

Thirteen polymorphisms were identified in the study group (Table 4) including: 2 polymorphisms in the KCNQ1 gene (exons 13 and 16), 6 polymorphisms in the $K C N H 2$ gene (exons 6,7 , $8,11$ and 12$), 4$ polymorphisms in the $S C N 5 A$ gene (exons 2, 12, 17 and 28) and 1 polymorphism in the KCNE1 gene in exon 3. These allele frequencies were similar in the hearing loss population and the general population. Twelve patients had a K897T polymorphism in the KCNH2 gene associated with the dysfunction of the potassium channel mediating IKr current. The Wilcoxon test was used to compare the QTc duration of the individuals with the found polymorphisms to the QTc duration of those without the polymorphisms. Only one (Y666Y) of the polymorphisms was associated with prolonged QTc reaching statistical significance $(\mathrm{p}=0.008)$. Due to the small number $(\mathrm{n}=7)$ of individuals carrying this polymorphism, these results have to be interpreted carefully and require further confirmation. 
Table 4. Polymorphisms.

\begin{tabular}{|c|c|c|c|c|c|}
\hline Gene & Change* & $\begin{array}{c}\text { Frequency } \\
\text { in control group }\end{array}$ & $\begin{array}{c}\text { Frequency } \\
\text { in patients with } \\
\text { hearing loss }\end{array}$ & $\mathbf{P}$ & Comments \\
\hline KCNQ1 exon 13 & S546S & $\operatorname{MAF}(A)=0.20$ & $\operatorname{MAF}(\mathrm{A})=0.165$ & NS & \\
\hline KCNO exon 16 & Y662Y & $\operatorname{MAF}(T)=0.118$ & $\operatorname{MAF}(T)=0.139$ & NS & \\
\hline$K C N H 2$ exon 6 & $\mathrm{~F} 513 \mathrm{~F}$ & $\operatorname{MAF}(A)=0.368$ & $\operatorname{MAF}(A)=0.34$ & NS & \\
\hline$K C N H 2$ exon 6 & |489| & $\operatorname{MAF}(A)=0.37$ & $\operatorname{MAF}(A)=0.32$ & NS & \\
\hline$K C N H 2$ exon 7 & L564L & $\operatorname{MAF}(A)=0.39$ & $\operatorname{MAF}(A)=0.29$ & NS & \\
\hline$K C N H 2$ exon 8 & Y652Y & $\operatorname{MAF}(\mathrm{A}) \mathrm{eu}=0.40$ & $\operatorname{MAF}(\mathrm{A})=0.609$ & 0.09 & Unfavorable allele $\mathrm{T}$ \\
\hline KCNH2 exon 11 & K897T & $\operatorname{MAF}(G)=0.129$ & $\operatorname{MAF}(G)=0.196$ & NS & $\begin{array}{l}\text { Occurs in splicing region, } \\
\text { regulatory impact }\end{array}$ \\
\hline KCNE1 exon 3 & S38G & $\operatorname{MAF}(A)=0.331$ & $\operatorname{MAF}(A)=0.29$ & NS & $\begin{array}{l}\text { Serine (allele A) seems } \\
\text { to be unfavorable }\end{array}$ \\
\hline SCN5A exon 2 & A29A & $\operatorname{MAF}(A)=0.22$ & $\operatorname{MAF}(\mathrm{A})=0.39$ & 0.26 & Unfavorable allele A \\
\hline SCN5A exon 12 & H558R & $\operatorname{MAF}(G)=0.22$ & $\operatorname{MAF}(G)=0.20$ & NS & Benign change, regulatory impact \\
\hline$S C N 5 A$ exon 17 & E1061E & $\operatorname{MAF}(T)=0.08$ & $\operatorname{MAF}(T)=0.07$ & NS & Rare change \\
\hline SCN5A exon 28 & D1818D & $\operatorname{MAF}(A)=0.49$ & $\operatorname{MAF}(\mathrm{A})=0.50$ & NS & \\
\hline KCNH2 exon 12 & A572D & $\operatorname{MAF}(A)=0.001$ & 2 cases & & $\begin{array}{l}\text { Very rare change of unknown } \\
\text { significance }\end{array}$ \\
\hline
\end{tabular}

*Amino acid abbreviations: $\mathrm{S}$ - serine, $\mathrm{Y}$ - tyrosine, $\mathrm{F}$ - phenylalanine, $\mathrm{K}$ - lysine etc.; MAF — minor allelic frequency based on $1000 \mathrm{Ge}$ nomes, SIFT and PolyPhen

\section{Discussion}

Our study population consisted of 1,080 subjects with hearing loss, including 441 children younger than 14 . Up to date, there is no data in the literature on QTc interval analysis within similar clinical context (hearing loss) and on such a large population. The largest study ever has been conducted in California. It has researched 707 children younger than 6 years old [6]. There is a published study of ECG changes in 162 Polish children aged between 3 and 15 years with a hearing loss. In that cohort, QTc prolongation above the reference value was found in 16 patients (9.9\% of the group), while high or intermediate probability of LQTS according to Schwartz's criteria was identified in $27(16.6 \%)$ children [7]. Furthermore, there has been a study published on 132 children with a hearing loss, among who $5(3.8 \%)$ patients were diagnosed with JL-N syndrome [8]. On the other hand, in 350 Turkish children with congenital hearing loss, who were between the ages of 6 and 19 years, LQTS (according to Schwartz criteria) was present in only $2(0.57 \%)$ patients (girls aged 14 and 15 years) [9]. In that Turkish study, the population of children was older than in our study. JL-N syndrome and LQTS can lead to sudden death at a very young age. According to Schwartz, the mortality reaches $20 \%$ within the $1^{\text {st }}$ year after the syncope and $50 \%$ within the following 10 years. On the other hand, in the study of 276 Thai children with congenital sensorineural hearing loss the prevalence of the JL-N syndrome was reported at the $0.7 \%$ level [10].

We have not detected a single case of JL-N syndrome among 1,080 studied subjects who were affected by various degrees of hearing loss. It seems to be related to low incidence of this disease in the Central European population. Similarly, the JL-N syndrome has not been detected in earlier mentioned study conducted in California [6]. Fraser et al. [11] estimated that the incidence of this syndrome in the pediatric population aged 4 to 15 years in England, Wales and Ireland was between 1.6 to 6 in 1,000,000. So far, the highest incidence of JL-N syndrome of at least 1:200,000 has been reported in Norway [12].

As noted, since we have diagnosed 5 patients with LQTS genotyping only 60 patients out of 1,027 patients with hearing loss, one can make an estimation, that in a hearing loss population, LQTS can be observed at least with the incidence of around 1 in 205 patients, which is much more than previously reported by Schwartz et al. [13] 1 in 2,500-3,000 patients. It should be emphasized that the proposed strategy can be used not only for 
the screening for the JL-N syndrome, but also, for the effective diagnosis of the LQTS.

The incidence of prolonged QTc in populations with a hearing loss was previously estimated at the level of approximately $4 \%[14,15]$. On the other hand, $2.5 \%$ of general neonatal population in Italy has been found to have QTc longer than $440 \mathrm{~ms}$. In this study, the incidence of LQTS was reported at the level of 1:2,000-2,500 [13]. In our study, we have found higher incidence of QT prolongation in patients with hearing loss than previously reported in the general population, and this was particularly noticeable in children. This requires further confirmation in research. Identification of the genetic background of this phenomenon and assessment of the associated risk of dangerous arrhythmias are needed as well. Our results are compatible with those reported by Rokicki et al. [7] and many other authors: Chinagudi et al. [14] (2 of 50 [4\%] children with congenital deafness had QTc longer than $450 \mathrm{~ms}$ ), Niaz et al. [15] (4 of 104 [3.8\%] of deaf children in Pakistan had QT longer than $440 \mathrm{~ms}$ ), Srivastava et al. [16] (deaf girls compared to healthy girls, had significantly longer QTc at rest and after exercise), El Habbal and Mahoney [17] (congenital sensorineural hearing loss was associated with prolonged QT interval in 52 children aged 8.35 years on average; mean QTc 417 ms ranging from $384 \mathrm{~ms}$ to $490 \mathrm{~ms}$ and Ilhan et al. [18] (QTc was significantly longer in 132 children with congenital hearing loss group vs. the control group; QTc measured $414 \pm 42 \mathrm{~ms}$ on average, ranging between $319 \mathrm{~ms}$ and $572 \mathrm{~ms}, 5$ patients had JL-N syndrome). It cannot be excluded that our method of measuring the QT interval is more accurate than manual measurement. If so, it may be required to modify reference values of the QTc intervals in the pediatric population. However, it should be emphasized that in our study, even in patients with abnormal QTc, the mean QTc interval was only slightly prolonged - still less than $490 \mathrm{~ms}$. Also, no arrhythmia or syncope were observed in any of studied patients and only 3 asymptomatic individuals had pathogenic mutations. Furthermore, despite including 3 so-called large LQTS genes (KCNQ1, KCNH2, SCN5A) responsible for approximately $75 \%$ of all LQTS cases and the KCNE1 gene (a so-called small LQTS gene) [19], we identified only 3 mutations in 6 patients that are known to be responsible for the occurrence of LQTS. Additionally, only $3(5 \%)$ patients with mutations had a significant increase in QTc on ECG screening. LQTS types 1 and 2 were found in 2 patients who had been unsuccessfully treated for incorrectly diagnosed epilepsy. As a result of genotyping performed during our study we made the diagnosis of LQTS and started appropriate treatment with good result. This emphasizes the need to differentiate epilepsy with LQTS. The role of the ECG, as an necessary investigation performed in any patient with syncope, along with genetic testing, which has a high diagnostic and prognostic value in LQTS, were both underlined [20,21]. Our study has once again proven that genetic testing in suspected LQTS should be used routinely in clinical practice [20]. Recently, the role of single nucleotide polymorphisms in $\mathrm{KCNH} 2$ and $S C N 5 A$ genes has been reported as important factor associated with some cardiac diseases. The knowledge about single nucleotide polymorphisms (SNPs) in these genes and their associations with LQTS is limited and controversial, though some studies have revealed longer QT intervals in people with the K897T polymorphism in the KCNH2 gene [22, 23]. H558R polymorphism in the $S C N 5 A$ gene was reported as possibly being able to modify expression of an arrhythmia causing mutations [24, 25]. We don't know if SNPs in genes which encode sodium and potassium channels in cardiomyocytes may also be associated in various hearing loss processes. In our study, the prevalence of particular SNPs was as in general population. Based on the findings of our study and on other reports we suspect the following alleles to be associated with prolonged QTc in this population: K897T allele of the KCNH2 gene, H558R allele of the SCN5A gene, and A29A allele of the $S C N 5 A$ gene, or any combination of these alleles, or a combination of these alleles with other genes. Further studies are necessary to prove this hypothesis or to explain the role these alleles play in mechanisms of hearing loss and the QTc prolongation with the inherent risk of arrhythmia. Last but not least, we demonstrated an efficient use of telemedicine to transmit the large amount of ECG studies for a review to a cardiology center. Only selected patients who required further investigations needed to be referred to cardiology clinic. Similar telemedicine approach to ECG screening can be used in other populations.

\section{Limitations of the study}

The size of the studied population was too small to encounter such rare syndromes as JN-L is. We noticed that it may be sometimes difficult to measure QT accurately, especially when T wave is flattened. Additionally, in children RR intervals vary significantly from beat to beat and this raises the issue of under- or overestimation of QTc. 
Relatively high incidence of QTc prolongation may be due to the method of measurement we used, which is possibly more accurate (enlarged and precise caliper) than manual measurement on ECG printed with the $25 \mathrm{~mm} / \mathrm{s}$ paper speed. We should point out that none of cited references used this kind of precise technique of measurement. Not all patients from the high-risk group reported for, and some patients refused to participate in further cardiac studies.

\section{Conclusions}

Our study confirms that JL-N syndrome is extremely rare in the population of people with hearing loss. QT interval prolongation seems to be more frequent in patients (particularly in children) with hearing impairment than in the general population; to explain this phenomenon further studies are required. In people with long QT interval and coexisting hearing loss, only genetic tests can confirm or rule out LQTS. A careful work up, including genetic testing, should always precede the diagnosis of epilepsy with LQTS. To elucidate the role of particular alleles further studies are necessary. It should be emphasized that ECG screening in a population of patients with hearing loss is important when additionally history of epilepsy, syncope or loss of consciousness is present.

The current technology enables ECG transmission and is very efficient in screening of large populations of patients with no overt heart disease. It allows an expert assessment of the results of the studies and gives an opportunity to single out patients who might have various heart diseases, including these with dangerous arrhythmia.

\section{Acknowledgements}

The work was funded by the National Science Center [Grant No. NN 402526739].

\section{Conflict of interest: None declared}

\section{References}

1. Schwartz PJ, Spazzolini C, Crotti L et al. The Jervell and Lange-Nielsen syndrome: Natural history, molecular basis, and clinical outcome. Circulation, 2006; 113: 783-790.

2. Kang SL, Jackson C, Kelsall W. Electrocardiogram screening of deaf children for long QT syndrome: Are we following UK national guidelines? J Laryngol Otol, 2011; 125: 354-356.

3. Morzaria S, Westerberg BD, Kozak FK. Evidence-based algorithm for the evaluation of a child with bilateral sensorineural hearing loss. J Otolaryngol, 2005; 34: 297-303.

4. Baranowski R, Wojciechowski D, Maciejewska M. Recommendations for the use of electrocardiographic diagnoses. Document prepared by the Working Group established by the Management Section and Telemedicine Noninvasive Electrocardiology Polish
Cardiac Society under the patronage of the Polish Cardiac Society. Kardiol Pol, 2010; 68 (supl. IV): 8-30.

5. Priori SG, Wilde AA, Horie M et al. Executive summary: HRS/ /EHRA/APHRS expert consensus statement on the diagnosis and management of patients with inherited primary arrythmia syndromes. Europace, 2013; 15: 1389-406.

6. Chang RR-K, Lan Y-T, Silka MJ et al. Genetic Variants for long QT syndrome among infants and children from a statewide newborn hearing screening program cohort. J Pediatr, 2014; 164: 590-595.

7. Rokicki W, Markiewicz-Łoskot G, Michalewska A, Włudarczyk W, Mizia M. Preliminary cardiological examinations in deaf children. Przegl Lek, 2002; 59: 737-739.

8. Tuncer C, Cokkeser Y, Komsuoglu B et al. Assessment of ventricular repolarization in deaf-mute children. Pediatr Cardiol, 2000; 21: 135-140.

9. Ocal B, Imamoglu A, Atalay S, Ercan Tutar H. Prevalence of idiopathic long QT syndrome in children with congenital deafness. Pediatr Cardiol, 1997; 18: 401-405.

10. Sopontammarak S, Khongphatthanayothin A, Sa-Nguanchua P. Prevalence of idiopathic long QT syndrome in congenital sensori-neural hearing loss students of Songkhla School for the Deaf. J Med Assoc Thai, 2003; 86: 1149-1155.

11. Fraser GR, Froggatt P, Murphy T. Genetically aspects of the cardioauditory syndrome of Jervell and Lange-Nielsen (congenital deafness and electrocardiographic abnormalities). Ann Hum Genet, 1964; 28: 133-157.

12. Tranebjaerg L, Bathen J, Tyson J, Bitner-Glindzicz M. Jervell and Lange-Nielsen syndrome: A Norwegian perspective. Am J Med Genet, 1999; 89: 137-146.

13. Schwartz PJ, Stramba-Badaiale M, Crotti L et al. Prevalence of the congenital long-QT syndrome. Circulation, 2009; 120: 1761-1767.

14. Chinagudi S, Patted SM, Herur A. A study of electrocardiographic changes In congenital deaf school children. Indian J Otolaryngol Head Neck Surg, 2010; 62: 44-48.

15. Niaz A, Rizvi SF, Khurram D. Prevalence of long QT syndrome and other cardiac defects in deaf-mute children. J Ayub Med Coll Abbottabad, 2011; 23: 5-8.

16. Srivastava RD, Pramod J, Deep J, Jaison TM, Singh S, Soni K. Electrocardiographic changes following exercise in the congenitally deaf school children: relationship with Jervell Lange Neilsen syndrome (the Long QT syndrome). Indian J Physiol Pharmacol, 1998; 42: 515-520.

17. El Habbal MH, Mahoney CO. QT interval in children with sensory neural hearing loss. Pacing Clin Electrophysiol, 2002; 25: 435-439.

18. Ilhan A, Tuncer C, Komsuoglu SS, Kali S. Jervell and LangeNielsen syndrome: Neurologic and cardiologic evaluation. Pediatr Neurol, 1999; 21: 809-813.

19. Tester DJ, Ackerman MJ. Genetics of long QT syndrome. Metodist Debakey Cardiovasc J, 2014; 10: 29-33.

20. Ackerman MJ, Priori SG, Willems S et al. HRS/EHRA expert consensus statement on the state of genetic testing for the channelopathies and cardiomyopathies: This document was developed as a partnership between the Heart Rhythm Society (HRS) and the European Heart Rhythm Association (EHRA). Europace, 2011; 13: 1077-1109.

21. MacCormick JM, McAlister H, Crawford J et al. Misdiagnosis of long QT syndrome as epilepsy at first presentation. Ann Emerg Med, 2009; 54: 26-32.

22. Pietila E, Fodstad H, Niskasaari E et al. Association between HERG K897T polymorphism and QT interval in middle-aged Finnish women. J Am Coll Cardiol, 2002; 40: 511-514.

23. Newton-Cheh C, Guo CY, Larson MG et al. Common genetic variation in $\mathrm{KCNH} 2$ is associated with QT interval duration: The Framingham Heart Study. Circulation, 2007; 116: 1128$-1136$.

24. Ye B, Valdivia CR, Ackerman MJ, Makielski JC. A common human SCN5A polymorphism modifies expression of an arrhythmia causing mutation. Physiol Genomics, 2003; 12: 187-119.

25. Laitinen P, Fodstad H, Piippo K et al. Survey of the coding region of the HERG gene in long QT syndrome reveals six novel mutations and an amino acid polymorphism with possible phenotypic effects. Hum Mutat, 2000; 15: 580-581. 